\title{
Spectroscopy Study of Polyvinyl Alcohol/Carbon Dots Composite Films
}

\author{
Permono Adi PUTRO ${ }^{1, *}$, Nurfina YUDASARI ${ }^{2}$, Isnaeni' ${ }^{2}$ and Akhiruddin MADDU ${ }^{1}$ \\ ${ }^{I}$ Department of Physics, Faculty of Mathematics and Natural Sciences, Bogor Agricultural University, \\ Bogor 16680, Indonesia \\ ${ }^{2}$ Research Center for Physics, Indonesian Institute of Sciences, Banten 15314, Indonesia
}

('Corresponding author's e-mail: permanenputro@apps.ipb.ac.id)

Received: 26 November 2019, Revised: 19 July 2020, Accepted: 20 August 2020

\begin{abstract}
The unique characteristic of carbon dots (C-dots), such as optical and electrical properties, have been integrated into polyvinyl alcohol (PVA) to realize composites with synergistic. In this work, C-dots have been synthesized from inner cassava peels using simple methods at low temperatures. The $\mathrm{C}$-dots were added to PVA, which is influenced the characteristic based on spectroscopy. The complex formation between PVA and C-dots was investigated by FTIR spectroscopy. The C-dots contributed to UV-Vis spectroscopy characteristic of PVA/C-dots with the absence of a new peak of absorbance spectra. Besides, C-dots also supported the electrochemical impedance spectroscopy characteristic of PVA/Cdots, so the highest ionic conductivity is induced by the enhancement of amorphous PVA when the c-dots content is increased.
\end{abstract}

Keywords: Carbon dots, Ionic conductivity, Polyvinyl alcohol, Spectroscopy

\section{Introduction}

Carbon dots (C-dots) are new nanomaterial-based carbon with a size below $10 \mathrm{~nm}$ that received intensive attention [1], as a potential alternative for carbon nanotubes (CNT) [2]. It is caused C-dots can be synthesized from materials that only containing a carbon atom, and the methods are faster also low cost than CNT [3]. The synthesize of C-dots from biomass based-natural resources are comparable with chemical source [4]. However, using biomass as a carbon source is a good carbon source for the preparation of C-dots, and can increase its economic value [5]. Some research reported a carbohydrate contained in cassava peels has the potential as a carbon source. Putro et al. reported that outer cassava peels can be synthesized easily using microwave-assisted [6]. Therefore, inner cassava peels also can be synthesized by hydrothermal methods [7], microwave [8], and simple carbonization in an oven [4]. Some of the featuring properties of C-dots are independent excitation-photoluminescence [9] and electrical conductivity [10], which are potential applications as optoelectronic devices.

An intensive study about C-dots combined into polymer matrices has attracted many researchers [11]. The strategy combining C-dots into solid polymer matrices can avoid nanoparticle coagulation, so their stability was relatively higher [12]. Besides, combining C-dots and polymers to form composites that have unique functionalities has been demonstrated [13]. Kumar et al. introduced nitrogen-doped Cdots into polyvinyl alcohol (PVA) to tune the refractive index of C-dots-PVA composite from c.a. 1.55 to 1.90 at $700 \mathrm{~nm}$ [14]. The Ambasankar et al. reported that the combination of C-dots having low states and insulating PVA could give rise to the charge trapping ability of resultant composites [2]; because the PVA can be dispersed and passivate C-dots, thus positive role in protecting C-dots from self-quenched [15]. PVA is chosen as the polymer matrix in the composite due to its prominent advantages such as high hydrophilicity, high optical transparency, and easy processability [16]. Furthermore, the hydroxyl group $(-\mathrm{OH})$ in the backbone of PVA makes it easier to form hydrogen bonding [17]. The oxygen and active 
hydrogen-rich $\mathrm{C}$-dots can serve as extra physical crosslinking points in PVA via strong hydrogen bonding interaction [18].

In this study, we present a simple route for producing a C-dots composite with 2 steps. In the $1^{\text {st }}$ step, C-dots were synthesized from inner cassava peels using simple carbonization in an oven as previously reported [4]. Then, the C-dots solution was blended into PVA solution and it was cast on the Teflon. However, the characterization of ionic conductivity associated with spectroscopy characteristics in PVA/C-dots has not been reported. So, we are interested in doing that.

\section{Materials and methods}

\section{Material}

Inner cassava peels were kindly supplied by the traditional market in Ciledug, Tangerang City, Indonesia. Polyvinyl alcohol $\left[-\mathrm{CH}_{2} \mathrm{CH}(\mathrm{OH})-\right]_{\mathrm{n}}$ with molecular weight 11,000 were purchased from Sigma-Aldrich. Aquadest is used as a non-chemical solvent.

\section{Synthesis of C-dots}

The synthesis methods of C-dots were adopted from Permono et al. [4]. Inner cassava peels put in the oven at $120{ }^{\circ} \mathrm{C}$ for $12 \mathrm{~h}$. Dried cassava peels were crushed by blender and sieved $40 \mathrm{mesh}$. Two gr powder cassava peels dissolved in $50 \mathrm{~mL}$ aquadest and it was stirred $420 \mathrm{rpm}$ at $200{ }^{\circ} \mathrm{C}$ for $1 \mathrm{~h}$. The solution was filtered by Whatman filter paper No. 1 to obtain a C-dots solution.

\section{Preparation of PVA/C-dots}

The preparation of PVA/C-dots methods was adopted from Roza et al. [19]. The PVA solution was made by 4 gr PVA powder which was dissolved into $200 \mathrm{~mL}$ aquadest. The PVA and C-dots solution were blended at 20/0.0, 19.5/0.5, 19/1.0, and 18/2.0 mL volume variations. The PVA/C-dots solution was cast on a Teflon and heated at $60{ }^{\circ} \mathrm{C}$ for $4 \mathrm{~h}$.

\section{Characterization}

The measurements of optical properties were characterized by using MAYA Ocean Optics Spectrophotometer to obtain spectra of absorbance, photoluminescence, and time-resolved photoluminescence. The ionic conductivity was determined using electrochemical impedance spectroscopy of HIOKI 3522-50 LCR HiTESTER with a range frequency of $50 \mathrm{~Hz}$ to $1 \mathrm{MHz}$ at room temperature. The Fourier transform infrared spectra were recorded by Thermo Scientific Seri Nicolet is 10 Smart iTR at 500 until $4,000 \mathrm{~cm}^{-1}$ with a resolution of $2 \mathrm{~cm}^{-1}$. The crystallinity degree measurement used X-ray Diffraction in Shimazu XRD-7000, with a $\mathrm{Cu} \mathrm{K}$ radiation $(\lambda=0.154 \mathrm{~nm})$ at $40 \mathrm{kV}$ and $30 \mathrm{~mA}$ in the 2 theta range of $5^{\circ}$ until $60^{\circ}$ at a speed of $2^{\circ} \mathrm{min}^{-1}$.

\section{Results and discussion}

\section{Carbon dots}

The C-dots solution was synthesized by using inner cassava peels as the raw materials. White cassava peels turned brown after being put into the oven at $120^{\circ} \mathrm{C}$ for $12 \mathrm{~h}$. It indicated an imperfect carbonization phase due to avoid bulk carbon formation. Therefore, cassava peels powder was dissolved by aquadest and filtered to obtain carbon nanoparticle solution, which was thought to be C-dots. The physical performance of carbon nanoparticle solution was yellowish when irradiated visible light source, and its green fluorescence when irradiated violet light source at $405 \mathrm{~nm}$. This fluorescence indicating the success of C-dots was formed. The physical performance of C-dots can be seen in Figure 1. 
http://wjst.wu.ac.th

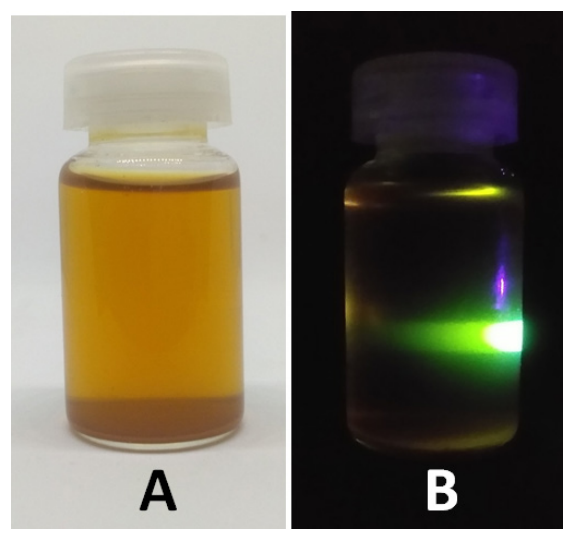

Figure 1 The physical performance of C-dots.

\section{The UV-Vis spectroscopy analysis}

The absorbance spectra of C-dots obtained by UV-Vis spectroscopy at 200 to $700 \mathrm{~nm}$ can be seen in Figure 2. The UV-Vis absorption spectrum depicted a typical optical absorption in the UV region, with a tail stretching into the visible range. Additionally, an obvious absorption characteristic peak at $311.26 \mathrm{~nm}$ was detected. The former was attributed to the $n-\pi^{*}$ transition of the $C=O$ bond $[20,21]$. Both of the optical peak absorbance appropriate with a result previously which synthesized the $\mathrm{C}$-dots from coriander leave [22]. The characteristic of the C-dots energy gap like organic molecular was an electronic transition that occurs from one energy level to the higher energy level. The electronic transition that involved ( $\sigma$ and $\pi$ ) bond, ( $\sigma^{*}$ and $\pi^{*}$ ) anti-bond and non-bonded orbital (n). but, $\pi \rightarrow \pi *$ and $n \rightarrow \pi *$ transition was very important for the energy transition of the C-dots agreement with the wavelength of visible light which appropriated with photoluminescence characteristic at visible light spectra region [23,24]. Nonetheless, $n$ $\rightarrow \pi *$ electronic transition was dominated in the C-dots absorbance spectra.

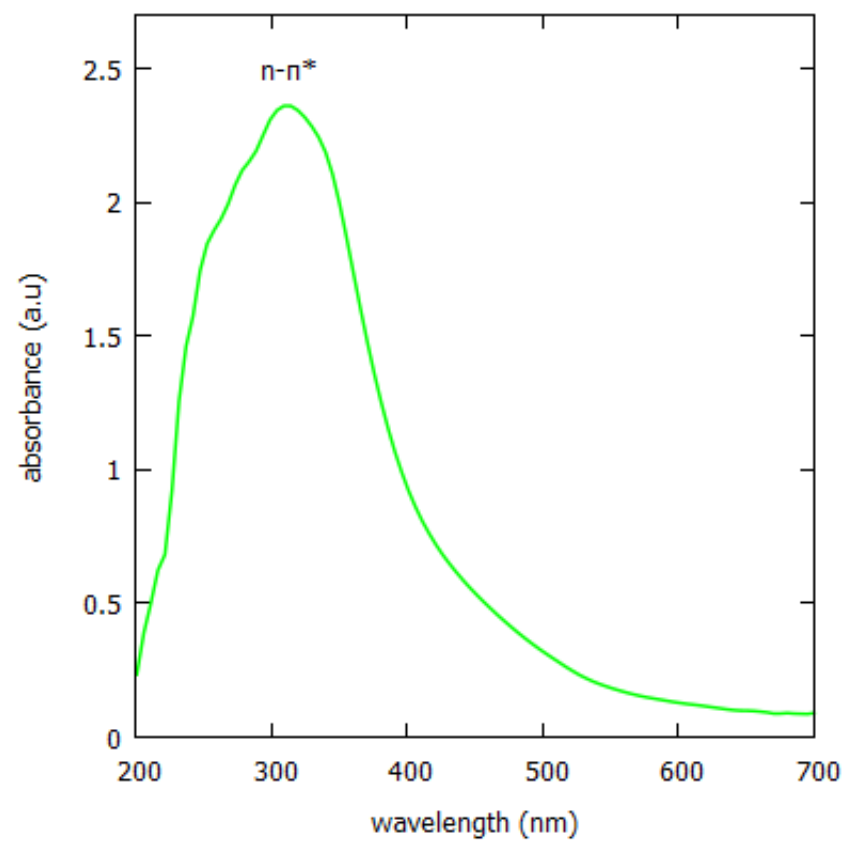

Figure 2 The absorbance spectra of C-dots. 


\section{The photoluminescence spectroscopy analysis}

Photoluminescence is the emission or emission of light from an excited state in an electronic transition spontaneously after absorbing light. The photoluminescence process can be observed in the position of the spectrum, dynamics, and efficiency to obtain relevant information. This spectrum informs about the energy difference between the excited state and the ground state which serves as the first indicator of material application $[7,25]$.

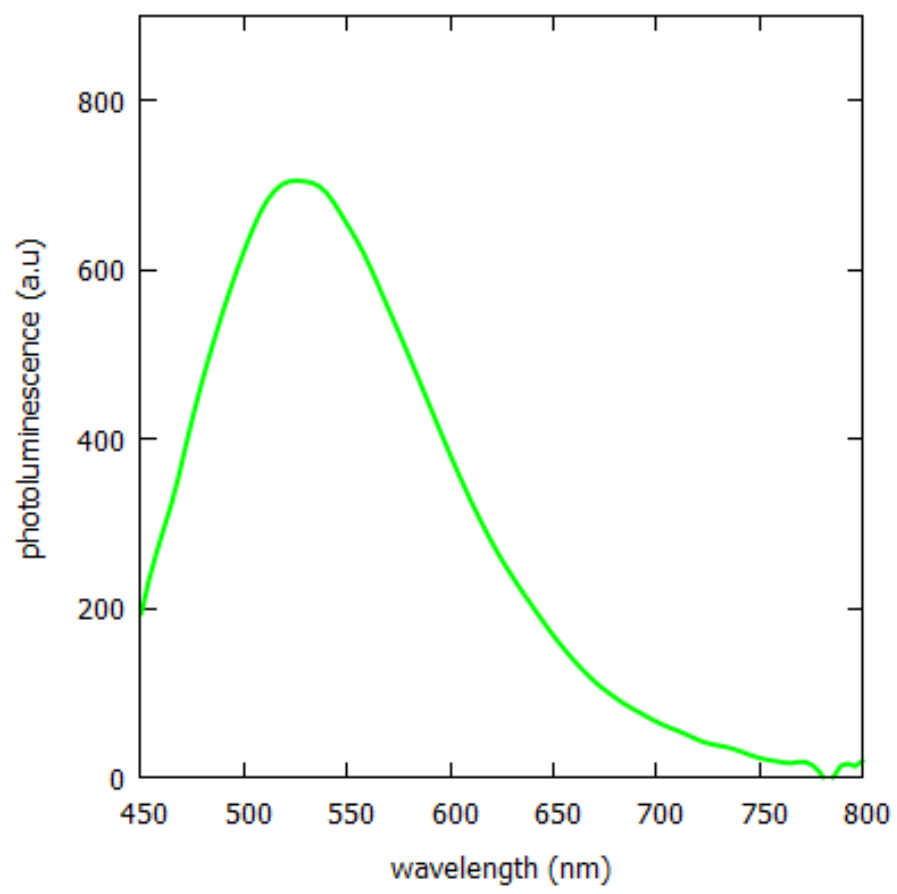

Figure 3 The photoluminescence spectra of C-dots.

The photoluminescence behavior of the C-dots is excited-dependent. These phenomena of the emission property may originate from the size of the C-dots, the availability of $\mathrm{sp}^{2}$ sites, aromatic conjugated structure, and the defects in the structure [26]. However, this study only one light source excited, its $420 \mathrm{~nm}$. The photoluminescence spectra of C-dots can be seen in Figure 3. The maximum photoluminescence peak of C-dots is $529.55 \mathrm{~nm}$. The broad peak of photoluminescence intensity at the wavelength $(\sim 500 \mathrm{~nm})$ was originated from the surface of C-dots [27].

\section{The time resolved-photoluminescence spectroscopy analysis}

The photoluminescence of C-dots was observed further by using time-resolved photoluminescence spectroscopy, to determine electron time decay or usually called lifetime [19]. The lifetime is an important characteristic of light-emitting nanoparticles to identify the potential applications. The lifetime measurement is used to determine the photoluminescence properties that show several energy levels [28], carried out under the excitation pulse laser and recorded after the excitation pulse finished [25]. 


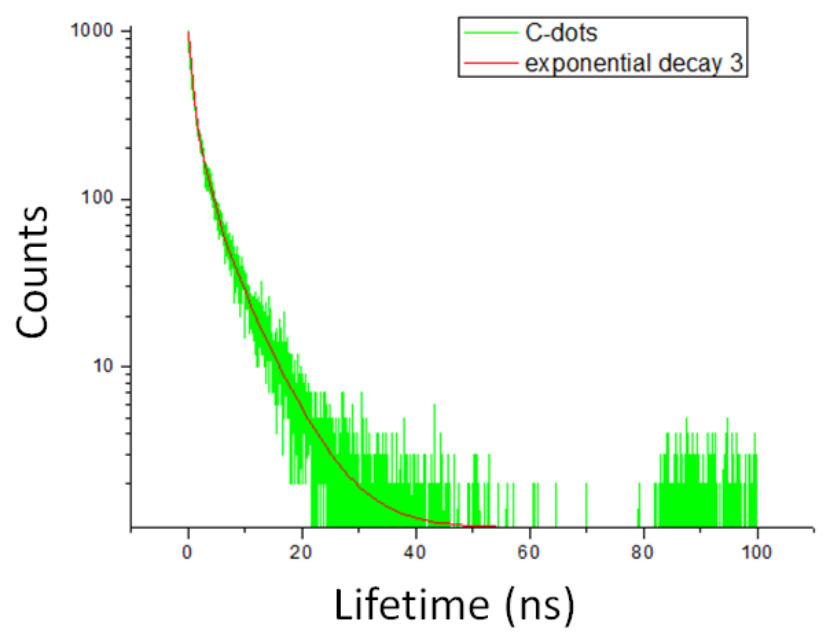

Figure 4 The time-resolved photoluminescence spectra of C-dots.

The time-resolved photoluminescence spectroscopy was employed to estimate the lifetime of C-dots and, further, explored by using the optical fluorescence properties. It was fitted by using triple exponential model as the Eq. (1) [29-31]:

$$
\begin{aligned}
& I(t)=\sum_{i} a_{i} \exp \left(\frac{-t}{\tau_{i}}\right) \\
& \tau_{i}=\frac{\sum a_{i} \tau_{i}^{2}}{\sum a_{i} \tau_{i}}
\end{aligned}
$$

Where $a_{i}$ and $\tau_{i}$ are multi-exponential decay components of amplitude and lifetime. The measurement of the average lifetime of C-dots can be obtained using Eq. (2) [30-34]. The time-resolved photoluminescence spectra of C-dots can be seen in Figure 4. Thus, the calculated average lifetime of the $\mathrm{C}$-dots is $3.54 \mathrm{~ns}$. This result is similar to the C-dots synthesized from inner cassava peels using microwave methods for $20 \mathrm{~min}$ is $3.43 \mathrm{~ns}$ [19].

\section{Polyvinyl alcohol/carbon dots}

C-dots were observed at solid phase while it combined into PVA matrix to formed PVA/C-dots composite films. The performance of PVA showed transparent film and changed yellowish that reflected the presence of C-dots. The physical performance of PVA and PVA/C-dots can be seen in Figure 5. 


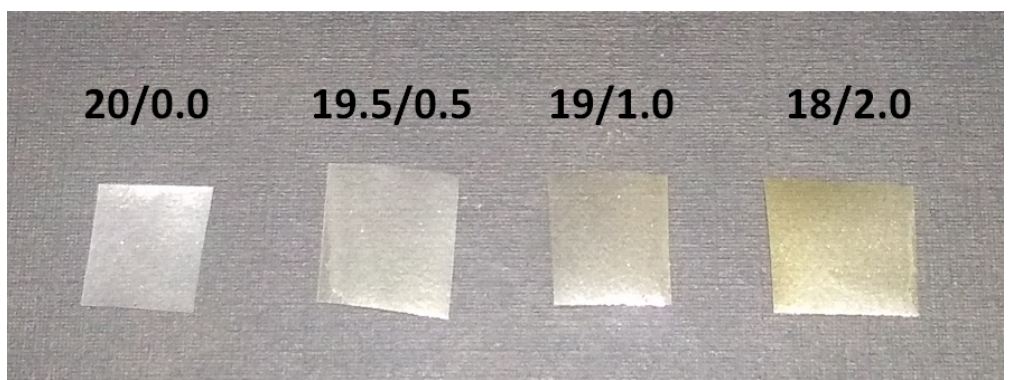

Figure 5 The physical performance of PVA and PVA-C-dots composites.

The X-ray diffraction analysis

The X-ray diffraction (XRD) measurement on PVA and PVA/C-dots was carried out to identify the effect of C-dots as nucleation agent in PVA, which will be influenced by the crystal degree of PVA as shown in Figure 6. The XRD spectra of PVA disclosed the characteristic peak of the semi crystal of PVA at $19.6^{\circ}$ [35], and its increasing amorphous with the addition of C-dots. The characteristic peaks of PVA semi-crystal were nearly not changed in PVA/C-dots, indicating that C-dot would not influence the semicrystal structure of PVA. These results turned back with $\mathrm{Hu}$ et al. that crystal degree of C-dot/PVA was higher than pure PVA, and increased along with the increase in the C-dot content, indicating that the addition of C-dots into PVA could increase the crystal degree of PVA [36].

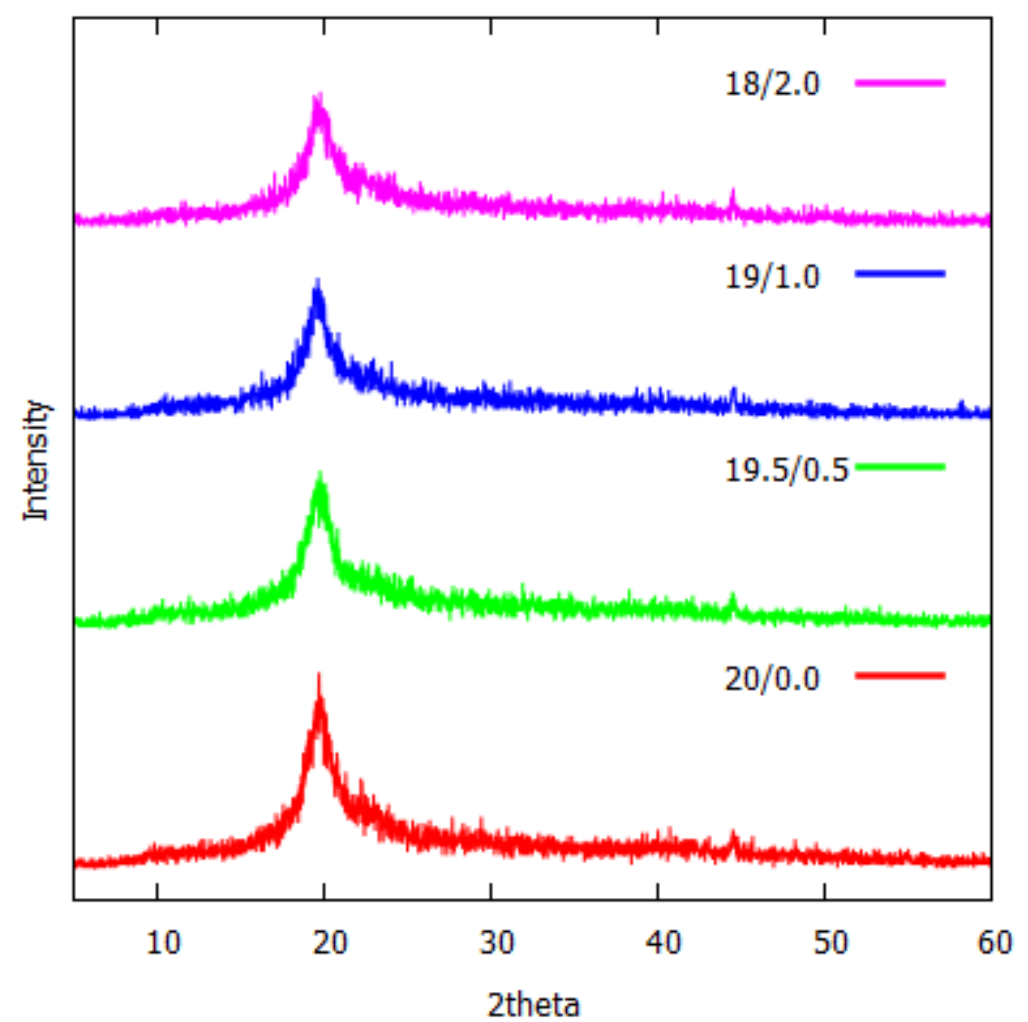

Figure 6 The X-ray diffraction spectra of PVA and PVA/C-dots. 


\section{The FTIR spectroscopy analysis}

The FTIR spectroscopy analysis of well-dispersed PVA and PVA/C-dots was conducted to reveal the chemical and molecular interaction of PVA and C-dots. The FTIR measurement for PVA films and PVA/C-dots films are presented in Figure 7. The -OH stretching band is very sensitive to hydrogen bonding [18]. The -OH stretching peak shifts to lower wavenumbers in the PVA/C-dots along with the increasing amount of C-dots, from 3,597.67 $\mathrm{cm}^{-1}$ of PVA to 3,579.73 $\mathrm{cm}^{-1}$ of PVA/C-dots (19/1.0) [37], which suggests that the strong hydrogen bonds were formed between PVA chains and C-dots [36]. Furthermore, it was found that the -OH stretching peak shifts to a higher wavenumber at PVA/C-dots from $3,579.73 \mathrm{~cm}^{-1}$ of $19 / 1.0$ to $3,606.25 \mathrm{~cm}^{-1}$ of $18 / 2.0$, which suggests the broken of the hydrogen bonding [38]. The $\mathrm{C}=\mathrm{O}$ stretching band at $1,655.93 \mathrm{~cm}^{-1}$ changes in intensity and widening in each sample, indicating the formation of H-bonding between the PVA and C-dots [14]. In addition, there is another shift in the $\mathrm{C}-\mathrm{H}$ bending peak position at $1,458.47 \mathrm{~cm}^{-1}$ of PVA and PVA/C-dots [12]. All the results confirmed the presence of strong hydrogen bonds between the surface hydroxyl group of PVA might play an important role in interacting with the oxygen-containing functional groups around the Cdots surfaces to form rigid hydrogen bonds [15,36]. Furthermore, PVA also acts as a surface passivation agent for the C-dots by forming a thin membrane around the surface of C-dots to prevent the adhesion force between C-dots and impurities from the environment [39].

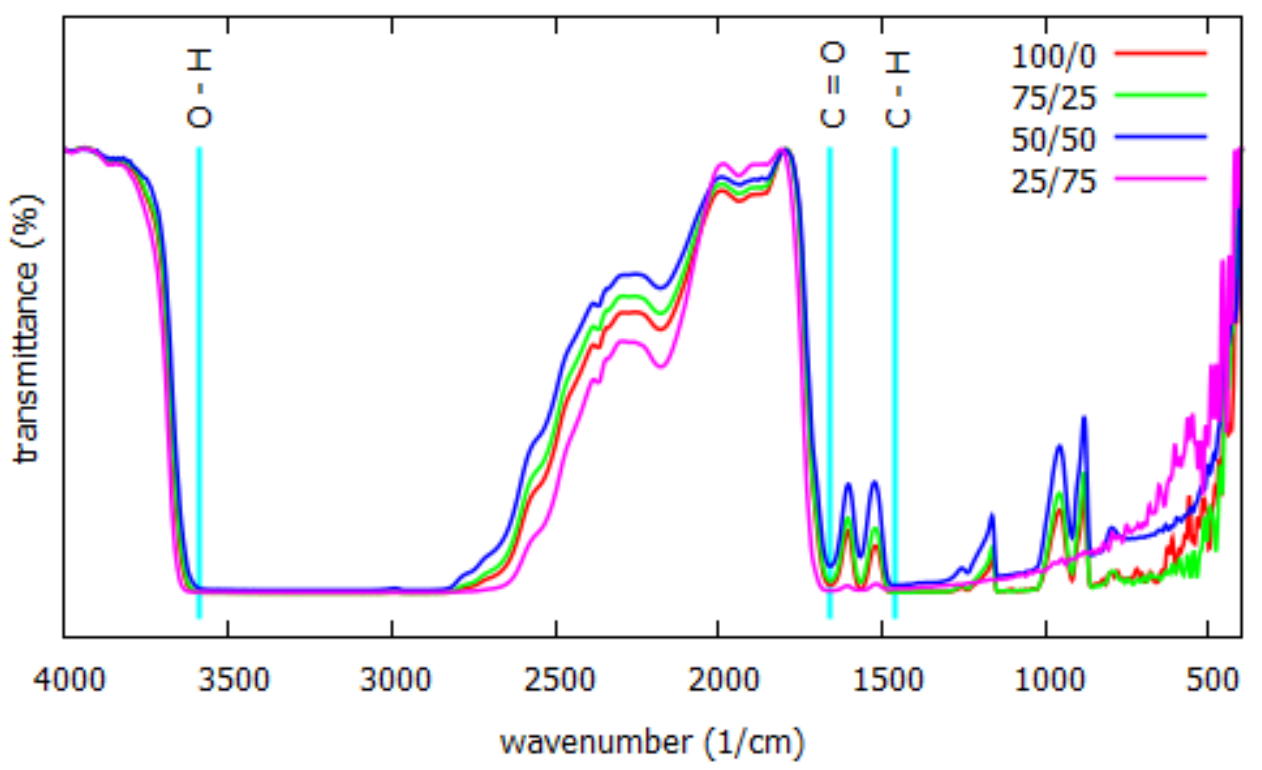

Figure 7 The infrared transmittance spectra of PVA and PVA/C-dots.

\section{The UV-Vis spectroscopy analysis}

The absorbance spectra of PVA and PVA/C-dots can be seen in Figure 8. In absorbance spectra of PVA only showed an absorbance peak at $203.28 \mathrm{~nm}$. However, the PVA/C-dots absorbance intensity enhanced and shifted at 19.5/0.5, 19/1.0, and $18 / 2.0$ were $210.90,225.65$, and $220.89 \mathrm{~nm}$, respectively. Besides, on PVA/C-dots presence a new shoulder indicating the C-dots absence at 19.5/0.5, 19/1.0, and $18 / 2.0$ was $298.42,288.02$, and 294.64 , respectively. These absorbance peaks associated with the transition $\pi \rightarrow \pi^{*}$ based on functional groups from $\mathrm{C}=\mathrm{O}$. These results are similar to Roza et al.'s discovery that the addition of C-dots to PVA contributed to the presence of a new absorbance peak at 274 $\mathrm{nm}$. The absorbance peak was not found on PVA absorbance spectra [19]. 


\section{The Electrochemical impedance spectroscopy}

The ionic conductivity measurement by using the electrochemical impedance spectroscopy. It was determined by using Eq. (3), and while the resistance value was obtained using Eq. (4) [40].

$$
\begin{aligned}
\sigma & =\frac{t}{R \cdot A} \\
R & =\frac{1}{G}
\end{aligned}
$$

Where $t$ is the thickness of the sample, $A\left(\mathrm{~cm}^{2}\right)$ the cross-sectional area of the film, $R$ is resistance, and $G$ is the condutance value was obtained from the electrochemical impedance spectroscopy measurement. The thickness of samples was found of $0.0002 \mathrm{~cm}$ by using a micrometer secrupt.

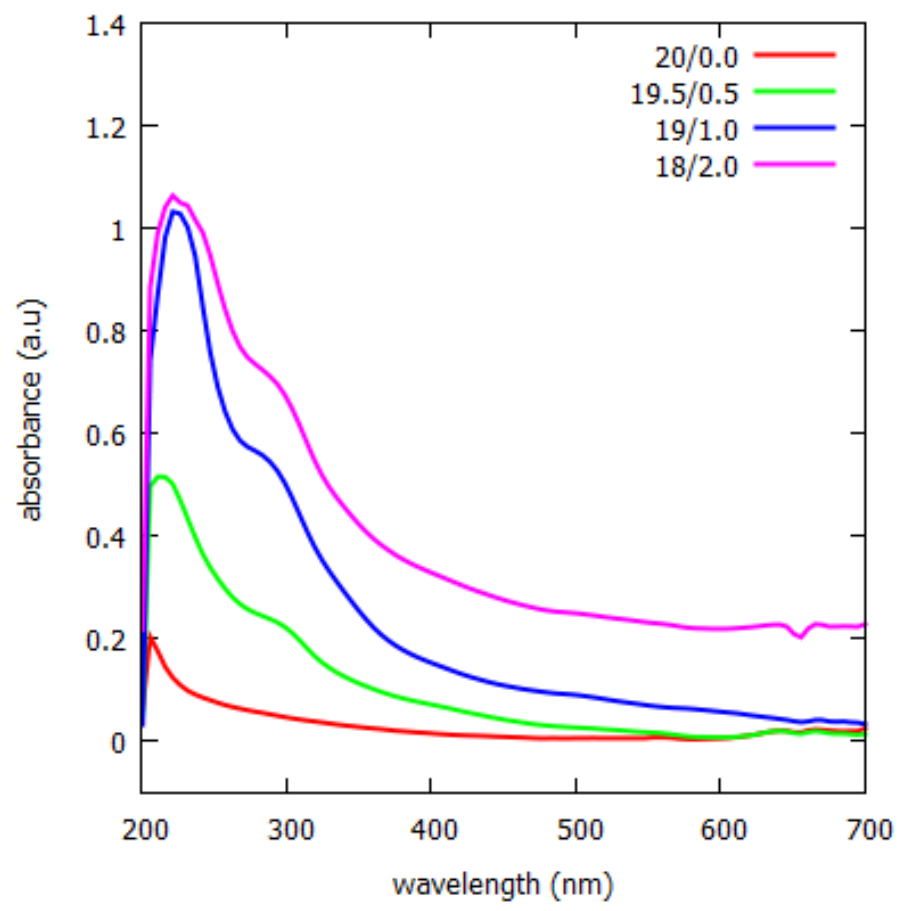

Figure 8 The absorbance spectra of PVA and PVA/C-dots. 


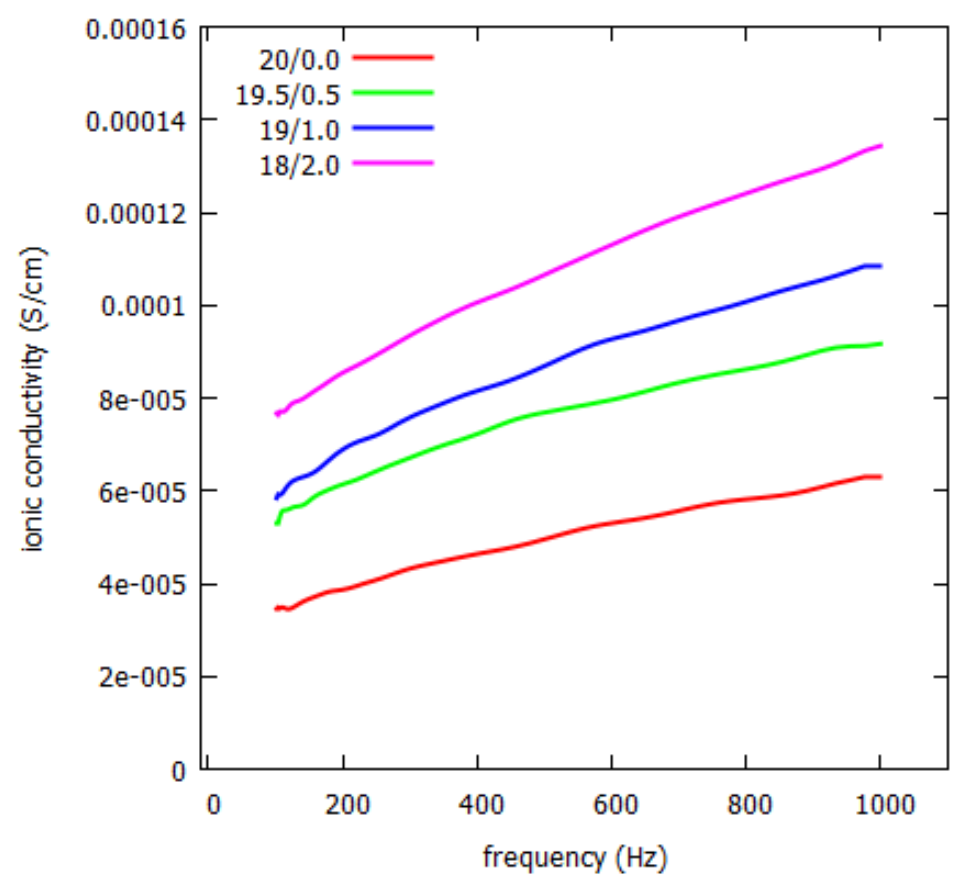

Figure 9 The ionic conductivity spectra of PVA and PVA/C-dots.

The ionic conductivity measurement was carried out to determine the effect of adding C-dots into the PVA. Based on the results of the previous XRD analysis in Figure 6, it was proven that the PVA crystal degree was measured after the incorporation of C-dots. The relationship between crystal degree and ionic conductivity was, further, investigated. The ionic conductivity is illustrated in Figure 9, which shows an increase in ionic conductivity when C-dots into PVA. The values of ionic conductivity PVA/Cdots $(20 / 0.0,19.5 / 0.5,19 / 1.0$ and $18 / 2.0)$ were $6.49 \times 10^{-5}, 9.16 \times 10^{-5}, 1.09 \times 10^{-4}, 1.3 \times 10^{-4} \mathrm{~S} / \mathrm{cm}$, respectively. Perhaps, this increase was due to the higher amorphous phase which was confirmed from the XRD analysis. These results are comparable with those found by Saadiah et al. revealing that the higher amorphous phase confirmed from XRD causing an increase in the value of ionic conductivity [35]. Ramli et al. [42] reported a similar finding, in which an increase in ionic conductivity could be caused by an increase in amorphous in the sample, which potentially encouraged ion transport.

\section{Conclusions}

In summary, we have successfully synthesized C-dots from inner cassava peels using simple methods using inner cassava peels for the synthesis of C-dots represents an economic, efficient, and environmentally friendly way, which is a significant large-scale commercial method for the synthesis of $\mathrm{C}$-dots. The strategy about C-dots combine into PVA can tune the characteristic spectroscopy and crystal degree. The C-dots playing of important role in the excellent of ionic conductivity value through increasing of crystal degree. These results have the potential to be applied as transparent conductive films based on the highest ionic conductivity on the sample of 18/2.0. 


\section{Acknowledgements}

This work was supported by Research Center for Physics - Indonesian Institute of Sciences and Ministry of Research and Technology and Higher Education Indonesia through Insensif Riset Sinas (INSINAS) grant on Active Packaging Based on $\mathrm{ZnO}$ nanoparticle at the budget year 2019 No. 15-INS1/PPK/E4/2019.

\section{References}

[1] R Das, R Bandyopadhyay and P Pramanik. Carbon quantum dots from natural resource: A review. Mater. Today Chem. 2018; 8, 96-109.

[2] KN Ambasankar, L Bhattacharjee, SK Jat, RR Bhattacharjee and K Mohanta. Study of electrical charge storage in polymer-carbon quantum dot composite. Chem. Sel. 2017; 2, 4241-7.

[3] LM Shen and J Liu. New development in carbon quantum dots technical applications. Talanta 2016; 156-157, 245-56.

[4] PA Putro, L Roza and Isnaeni. Precursor concentration effect on optical properties of carbon dots from cassava's peels. J. Phys. Theor. Appl. 2018; 2, 43-52.

[5] W Meng, X Bai, B Wang, Z Liu, S Lu and B Yang. Biomass-derived carbon dots and their applications. Energy Environ. Mater. 2019; 2, 172-92.

[6] PA Putro, L Roza and Isnaeni. Karakterisasi sifat optik C-dots dari kulit luar singkong menggunakan teknik microwave. J. Teknol. Technoscientia 2019; 11, 128-36.

[7] PA Putro, L Roza and Isnaeni. The effect of poly (ethylene glycol) on the photoluminescence properties of carbon dots from cassava peels synthesized by hydrothermal methods. SPEKTRA Jurnal Fisika dan Aplikasinya 2019; 4, 11-20.

[8] PA Putro, L Roza and Isnaeni. Photoluminescence properties of poly (ethylene glycol) passivated carbon dots from cassava peels. Indones. J. Sci. Educ. 2019; 3, 76-81.

[9] W Kwon and SW Rhee. Facile synthesis of graphitic carbon quantum dots with size tunability and uniformity using reverse micelles. Chem. Commun. 2012; 48, 5256-8.

[10] H Nan, Y Zhang, H Wei, H Chen, C Xue, G Yang, S Zou, G Wang and H Lin. Low-cost and environmentally friendly synthesis of an $\mathrm{Al}^{3+}$ and $\mathrm{Mn}^{4+}$ co-doped $\mathrm{Li}_{4} \mathrm{Ti}_{5} \mathrm{O}_{12}$ composite with carbon quantum dots as an anode for lithium-ion batteries. RSC $A d v .2019 ; 9$, 22101-5.

[11] SN Baker and GA Baker. Luminescent carbon nanodots: Emergent nanolights. Angew. Chemie 2010; 49, 6726-44.

[12] SB Aziz, AQ Hassan, SJ Mohammed, WO Karim, MFZ Kadir, HA Tajuddin and NNMY Chan. Structural and optical characteristics of PVA:C-Dot composites: Tuning the absorption of ultra violet (UV) region. Nanomaterials 2019; 9, 216.

[13] Q Hoang, V Mai, D Nguyen, DQ Truong and X Mai. Crosslinking induced photoluminescence quenching in polyvinyl alcohol-carbon quantum dot composite. Mater. Today Chem. 2019; 12, 16672.

[14] VB Kumar, AK Sahu, ASM Mohsin, X Li and A Gedanken. Refractive-index tuning of highly fluorescent carbon dots. ACS Appl. Mater. Interfaces 2017; 9, 28930-8.

[15] ZC Jiang, TN Lin, HT Lin, MJ Talite, TT Tzeng, CL Hsu, KP Chiu, CAJ Lin, JL Shen and CT Yuan. A facile and low-cost method to enhance the internal quantum yield and external lightextraction efficiency for flexible light-emitting carbon-dot films. Sci. Rep. 2016; 6, 19991.

[16] P Song, Z Xu and Q Guo. Bioinspired strategy to reinforce PVA with improved toughness and thermal properties via hydrogen-bond self-assembly. ACS Macro. Lett. 2013; 2, 1100-4.

[17] P Song, Z Xu, Y Lu and Q Guo. Bioinspired strategy for tuning thermal stability of PVA via hydrogen-bond crosslink. Compos. Sci. Technol. 2015; 118, 16-22.

[18] G Yang, X Wan, Y Liu, R Li, Y Su, X Zeng and J Tang. Luminescent poly (vinyl alcohol)/carbon quantum dots composites with tunable water-induced shape memory behavior in different $\mathrm{pH}$ and temperature environments. ACS Appl. Mater. Interfaces 2016; 8, 34744-54. 
http://wjst.wu.ac.th

[19] L Roza, PA Putro and Isnaeni. Ultrasonic-assisted melt blending for polyvinyl alcohol/carbon dots luminescent flexible films. AIP Conf. Proc. 2019; 2169, 060008.

[20] YL Wang, YQ Zhao, Y Zhang, F Zhang, XT Feng, L Chen, YZ Yang and XG Liu. A single-phase heteroatom doped carbon dot phosphor toward white light-emitting diodes. RSC Adv. 2016; 6, 38761-8.

[21] Y Wang, Y Zhao, F Zhang, L Chen, Y Yang and X Liu. Fluorescent polyvinyl alcohol films based on nitrogen and sulfur co-doped carbon dots towards white light-emitting devices. New J. Chem. 2016; 40, 8710-6.

[22] A Sachdev and P Gopinath. Green synthesis of multifunctional carbon dots from coriander leaves and their potential application as antioxidants, sensors and bioimaging agents. Analyst 2015; 140 , 4260-9.

[23] A Fadllan, P Marwoto, MP Aji, Susanto and RS Iswari. Synthesis of carbon nanodots from waste paper with hydrothermal method. AIP Conf. Proc. 2017; 1788, 030069.

[24] Isnaeni, Y Herbani and MM Suliyanti. Concentration effect on optical properties of carbon dots at room temperature. J. Lumin. 2018; 198, 215-9.

[25] O Kozák, M Sudolská, G Pramanik, P Cígler, M Otyepka and R Zbořil. Photoluminescent carbon nanostructures. Chem. Mater. 2016; 28, 4085-128.

[26] C Lee, B Pant, A Alam, T An, HJ Chung, ST Hong, SJ Park, M Park and HY Kim. Biocompatible and photoluminescent keratin/poly (vinyl alcohol)/carbon quantum dot nanofiber: A novel multipurpose electrospun mat. Macromol. Res. 2016; 24, 924-30.

[27] D Bhattacharya, MK Mishra and G De. Carbon dots from a single source exhibiting tunable luminescent colors through the modification of surface functional groups in ORMOSIL films. $J$. Phys. Chem. C 2017; 121, 28106-16.

[28] BP Jiang, YX Yu, XL Guo, ZY Ding, B Zhou, H Liang and XC Shen. White-emitting carbon dots with long alkyl-chain structure: Effective inhibition of aggregation caused quenching effect for label-free imaging of latent fingerprint. Carbon 2018; 128, 12-20.

[29] Q Li, M Zhou, M Yang, Q Yang, Z Zhang and J Shi. Induction of long-lived room temperature phosphorescence of carbon dots by water in hydrogen-bonded matrices. Nat. Commun. 2018; 9 , 734.

[30] JR Lakowicz. Principles of fluorescence spectroscopy. Springer, USA, 2006.

[31] T Yoshinaga, Y Iso and T Isobe. Particulate, structural, and optical properties of D-glucose-derived carbon dots synthesized by microwave-assisted hydrothermal treatment. ECS J. Solid State Sci. Technol. 2018; 7, R3034-R3039.

[32] X Dong, L Wei, Y Su, Z Li, H Geng, C Yang and Y Zhang. Efficient long lifetime room temperature phosphorescence of carbon dots in a potash alum matrix. J. Mater. Chem. C 2015; 3, 2798-801.

[33] M Chang, L Li, H Hu, Q Hu, A Wang, X Cao, X Yu, S Zhang, Y Zhao, J Chen, Y Yang and J Xu. Using fractional intensities of time-resolved fluorescence to sensitively quantify NADH/NAD ${ }^{+}$with genetically encoded fluorescent biosensors. Sci. Rep. 2017; 7, 4209.

[34] ZL Wu, P Zhang, MX Gao, CF Liu, W Wang, F Leng and CZ Huang. One-pot hydrothermal synthesis of highly luminescent nitrogen-doped amphoteric carbon dots for bio- imaging from bombyx mori silk: Natural proteins. J. Mater. Chem. B. 2013; 1, 2868-73.

[35] MA Saadiah, D Zhang, Y Nagao, SK Muzakir and AS Samsudin. Reducing crystallinity on thin film based CMC/PVA hybrid polymer for application as a host in polymer electrolytes. J. Non. Cryst. Solids 2019; 511, 201-11.

[36] $\mathrm{M} \mathrm{Hu}, \mathrm{X} \mathrm{Gu}, \mathrm{Y} \mathrm{Hu}, \mathrm{Y}$ Deng and C Wang. PVA/carbon dot nanocomposite hydrogels for simple introduction of Ag nanoparticles with enhanced antibacterial activity. Macromol. Mater. Eng. 2016; 301, 1352-62.

[37] S Wu, W Li, W Zhou, Y Zhan, C Hu, J Zhuang, H Zhang, X Zhang, B Lei and Y Liu. Large-scale one-step synthesis of carbon dots from yeast extract powder and construction of carbon dots/PVA fluorescent shape memory material. Adv. Opt. Mater. 2018; 6, 1701150. 
http://wjst.wu.ac.th

[38] Q Bai, G Zhang, B Xu, X Feng, H Jiang and H Li. Thermal and water dual-responsive shape memory poly (vinyl alcohol) $/ \mathrm{Al}_{2} \mathrm{O}_{3}$ nanocomposite. $R S C A d v .2015 ; \mathbf{5}, 91213-7$.

[39] M Taspika, FA Permatasari, BW Nuryadin, TR Mayangsari and F Iskandar. Simultaneous ultraviolet and first near-infrared window absoprtion of luminescent carbon dots/PVA composite film. RSC Adv. 2019; 9, 7375-81.

[40] Irzaman, R Erviansyah, H Syafutra, A Maddu and Siswadi. Studi konduktivitas listrik film tipis Ba $0.25 \mathrm{Sr} 0.75 \mathrm{TiO} 3$ yang didadah ferium oksida (BFST) menggunakan metode chemical solution deposition. Berk. Fis. 2010; 1, 33-8.

[41] MA Ramli and MINM Isa. Structural and ionic transport properties of protonic conducting solid biopolymer electrolytes based on carboxymethyl cellulose doped ammonium fluoride. J. Phys. Chem. B 2016; 120, 11567-73.

[42] MN Hafiza and MIN Isa. Solid polymer electrolyte production from 2-hydroxyethyl cellulose: Effect of $\mathrm{NH}_{4} \mathrm{NO}_{3}$ composition on its structural properties. Carbohydr. Polym. 2017; 165, 123-31. 